\title{
Development and Conflict Sensitivity: A Case Study of the Application of PCIA in Pakistan
}

\author{
Zahid Shahab Ahmed
}

\begin{abstract}
Since the mid-1990s the development community has focused significant attention on the potential and actual impact of development interventions on conflict resolution and peacebuilding in conflict-ridden and post-conflict zones. This has included the formulation and deployment of diverse concepts and tools of conflict sensitivity, including Peace and Conflict Impact Assessment (PCIA). Over the last 15 years the intent and application of PCIA has varied across the world. Mindful of this diversity, this article draws lessons from the application of PCIA in Pakistan, arguing that context-specific lessons are required to inform and shape the next phase of PCIA's development and application, thus ensuring that it is increasingly beneficial to all stakeholders.
\end{abstract}

Keywords PCIA, conflict sensitivity, development, peacebuilding, Pakistan

\section{Introduction}

Peace and Conflict Impact Assessment (PCIA), a tool used in the practice of conflict sensitivity, has been applied, along with the famous "do no harm" framework developed by Mary Anderson (1999), in different situations around the world. According to Abitbol $(2014,7)$, "over the last 15 years, PCIA has proven itself an adaptive analytic technology and discursive political practice." What makes PCIA different from other tools is its equal focus on sensitivity to both peace and conflict issues in conflict-affected and conflict-prone regions. PCIA demands attention to factors that drive conflict as well as peace. Although PCIA has been accepted in policymaking circles and by some international development organizations (e.g., Friedrich Ebert Stiftung), the tool has been implemented "varyingly" (McCandless 2014, 1). PCIA's application in letter and spirit has proved to be beneficial to peace and development in places affected by conflict, including, for example, in Mindanao in the Philippines (MacabuacFerolin and Constantino 2014, 10). Between 2005 and 2008, PCIA also emerged 
as an important practice of international development organizations in Pakistan. However, PCIA's flourishing was soon constrained by local and international factors. This article examines the reasons behind the limited and incomplete application of PCIA in Pakistan, a country that is faced with various forms of sectarian, ethnic, and inter-religious conflict. It is motivated by a desire to contribute to a meaningful dialogue around PCIA's significance and application for development work in Pakistan.

Towards this end, this article addresses the following questions: What are the practices and constraints of PCIA's application in Pakistan, and what can we learn from such a contextual analysis? This is a timely discussion given the flourishing of international peacebuilding organizations in Pakistan, including the United States Institute of Peace (USIP), International Alert, Saferworld, Search for Common Ground (SGCG), and others. It is hoped that lessons drawn from earlier phases of PCIA's implementation can support better organizational practices today.

The article begins with a brief analysis of the national context. This is followed by a section on perceptions of foreign aid agencies in Pakistan, mindful of an increase in anti-Western sentiment catalyzing aggression against these agencies. Having identified some contextual challenges, the article next discusses PCIA's theory and practice in Pakistan. In conclusion, a series of recommendations are proposed for improving the effective use of PCIA/conflict sensitivity in Pakistan and more broadly.

A two-pronged methodology was used in gathering data for this article. First, the analysis is significantly informed by the author's own professional work and field experience in Pakistan between 2006 and 2008. During that period the author implemented research and PCIA exercises on behalf of international development agencies (IDAs) ${ }^{1}$ in several conflict contexts and communities, including Khyber Pakhtunkhwa (KP) and Sindh. In 2006 this author conducted face-to-face interviews with some 20 local development workers employed by IDAs involved in project implementation in KP. In an effort to capture the level of awareness of PCIA in Pakistan, a short survey was conducted with 97 local and international nongovernmental organizations (NGOs). This survey sought to assess peacebuilders' knowledge of conflict sensitivity and PCIA. A total of 29 responses were received on the application of PCIA in Pakistan and these inform the analysis that follows. In short, this survey's results point to the fact that the majority of peacebuilders in Pakistan know little about PCIA and/or do not employ PCIA in their work.

\section{Pakistan's National Context}

According to an official estimate, Pakistan had a population of $183,919,765$ in 
2013 (Population Census Organization 2013). The last complete census in 1998 indicated religious affiliation as follows: $96.28 \%$ were Muslim and the remaining $3.72 \%$ belonged to minority groups that included Christians (1.59\%), Hindus (1.60\%), Qadianis/Ahmadis (0.22\%), and others (0.32\%) (Census of Pakistan 1998). There are five major ethno-regional communities in Pakistan: Balochs living in Balochistan, Muhajirs and Sindhis mainly living in Sindh, Punjabis living in Punjab, and Pushtuns living in KP. The country also has other religious and sectarian groups such as Kalasha, Parsis, Sikhs, and Shia Muslim sects, including Ismailis and Bohras (Malik 2005).

Pakistan is faced with multiple local and international challenges that must be considered when attempting to understand the significance of PCIA in development projects. Regarding external factors, there are tensions existing between Pakistan and its neighbors. Indeed, Pakistan's very location in South Asia generates significant geopolitical challenges to peacebuilding. Pakistan shares an eastern border with India and a northeastern border with China. It borders Iran on its southwest side, and Afghanistan runs along its western and northern edge. The Arabian Sea is Pakistan's southern boundary. Pakistan has experienced ongoing rivalry with India since 1947, which has led to three major wars between the two countries.

The so-called "war on terror" has generated continuous security operations by Pakistani troops in the Federally Administered Tribal Areas (FATA) as well as drone strikes by the United States. The issue of drone strikes has already created tensions between the ruling federal party (Pakistan Muslim League: Nawaz) and the ruling party of Khyber Pakhtunkhwa (Pakistan Tehrik Insaf, or PTI). Under the leadership of Imran Khan, the PTI has demanded that the government create an action-oriented policy on ending U.S. drone strikes on the basis that such actions by outsiders are a clear violation of the country's sovereignty. The ongoing war on terror is a significant factor responsible for people's negative perceptions of Western elements in general and Western development assistance in particular.

Within Pakistan security problems exist in the form of religious extremism, terrorism, political violence, and sectarianism. While there are no exact figures, it is clear that, since 2001, various forms of violence have changed the ethnic picture and distribution in the country. Such violence includes terrorism, counterterrorism security operations, as well as ethnic and political violence. Over the last decade, thousands of people from conflict-ridden areas have moved to secure locations in Punjab, mostly Lahore and the Islamabad Capital Territory. A newspaper report found an increase of 100,000 eligible voters in the relatively short span of five years in Islamabad (Dawn 2012). A major reason behind this increase is the influx of settlers from KP, FATA, and Karachi.

There are multiple internal conflict drivers in Pakistan that form around gender, religion, caste, language, ethnicity, and the dominance of the military in political affairs. Facing a resurgence of nationalists at home, an ongoing conflict 
with India to the east, and with volatile Afghanistan to the north, Pakistan is in a critical situation. The situation is further exacerbated by a lack of democratization, the continued dominance of the military, and political monopolies of landed and capitalist elites. Together, these factors have constrained the space for the pursuit of peaceful resolution to the many conflicts that risk violent escalation and continue to threaten the country's federal structure. In addition, civil society is relatively weak and has little space to influence the course of policymaking. A cumulative effect of all these factors is seen in the form of Pakistan's ranking in some relevant reports. In the Global Peace Index, the country was recently ranked 154 out of 162 countries, which means that the state of peace is very low (IEP 2014a, 6). The Global Terrorism Index placed Pakistan at third most affected out of 124 countries (IEP 2014b, 14).

The army remains strong with a prominent role in the country's civil affairs, especially while dealing with the massive problem of terrorism. The country also comprises various regional, sub-regional, and local identity groups that are juxtaposed against a weak national identity. Since Pakistan's 1947 independence governments have consistently failed to promote a collective identity, and this was a major reason for East Pakistan's separation and Bangladesh's 1971 independence. Consequently, Pakistan is vulnerable to conflict at various levels. The evidence of conflicts and security challenges can be seen in the form of ongoing counterterrorism operations in FATA, the Baluch insurgency in Baluchistan, ethnic and political violence in Sindh, the nationwide wave of terrorist attacks, and various forms of sectarian violence.

In addition, most governments of Pakistan have failed to formulate and implement effective economic and development policies, leading to a growing gap between haves and have-nots. If the poverty line is set at US\$2 a day, then half of the country lives in poverty, according to Finance Minister Ishaq Dar (Dawn 2014). Further, public institutions have been unable to fulfil their responsibilities, in part due to rampant corruption. Nonetheless, a recent study conducted on foreign aid found that aid is having a positive impact on economic growth in Pakistan (Javid and Qayyum 2011). The quality of such development interventions would undoubtedly be improved by greater contextual understanding and conflict-sensitive project planning, two key aspects of PCIA. As will be analyzed later in this article, PCIA develops conflict and cultural sensitivity within development projects. Therefore, PCIA can be helpful in enhancing development efforts in all parts of Pakistan, though not without encountering serious obstacles.

\section{National Perceptions of Foreign Aid in Pakistan}

International development interventions are viewed with suspicion in Pakistan. 
There is a nascent though real sentiment in some quarters that aid agencies are fulfilling a Western, anti-Islamic agenda through the promotion of non-Islamic values under the camouflage of development activities. This trust deficit is mostly associated with aid coming from the United States. Indeed, Western organizations are sometimes perceived as following a U.S. agenda. Notably, a large number of Muslim clerics belonging to fundamentalist and extremist schools of thought propagate this negative perception of international development programs in Pakistan (Ahmed 2011).

Such negative perceptions are further bolstered by the intimate ties cultivated between the United States and Pakistan over the last decade. According to Ayesha Siddiqa $(2007,35)$, a prominent Pakistani researcher:

Since the alignment began after 9/11, Washington has given Pakistan assistance worth US $\$ 10$ billion. This includes the monthly payment of US $\$ 100$ million in direct support of Pakistan army operations in the tribal belt. Other components of the aid package include military hardware and training. The money is being paid to carry out certain tasks ... US financial and military assistance to Pakistan has always come with strings attached-and it will be used to tweak the Pakistani establishment whenever the need arises.

Since 2001 anti-Western sentiment within Pakistan has created difficulties for the work of foreign aid agencies. A recent wave of violence took place against health workers involved in a polio vaccination campaign in KP. By the end of 2012, the Pakistani Taliban and their allies had killed 18 women health workers because the Taliban asserted that polio drops were part of a Western conspiracy to sterilize Muslims (The Economist 2012). Attacks on polio workers continue and by late 2014 had claimed more than 60 lives (Al Jazeera 2014).

Attacks on aid workers are not exclusive to the case of Pakistan (see Table 1). In the 2006-2008 period, three quarters of total attacks on aid workers globally took place in Sudan, Afghanistan, Somalia, Chad, Iraq, and Pakistan (Ahmed 2011, 6). Such attacks tend to occur for the following reasons: 1) Aid workers are perceived as friends of the "enemy"; 2) the attacked organization is the primary target rather than the individual; or 3) the delivery of aid to a particular group of people is opposed (Stoddard, Harmer, and DiDomenico 2009, 4-5). Attacks on development/NGO workers at the hands of extremist elements in Pakistan are mostly directed at foreigners, but locals who associate or work with foreigners are also often targets. This "anti-development worker" sentiment is not widespread, but rather held by a limited though vocal number of Pakistanis.

Due to the NATO-led military alliance in Afghanistan, all Western NGOs have been viewed with suspicion and concern. Attacks have specifically taken place against foreign and local workers of Plan International and USAID in KP province. This province is known to harbor pro-Taliban militants who have 
Table 1. Countries with Most Attacks on Aid Workers, 2013

\begin{tabular}{c|c}
\hline \hline Country & Number of Deaths \\
\hline Afghanistan & 81 \\
Syria & 43 \\
South Sudan & 35 \\
Pakistan & 17 \\
Sudan & 16 \\
Somalia & 8 \\
DRC & 7 \\
Kenya & 7 \\
CAR & 6 \\
Yemen & 6 \\
\hline
\end{tabular}

Source: Stoddard, Harmer, and Ryou. 2014, 2.

bombed the offices of NGOs in the past, alleging that international development agencies were trying to undermine their version of Islam. For example, they are highly critical of projects focusing on gender equality and women's empowerment.

In February 2008 armed men opened fire and hurled grenades at the office of Plan International in Mansehra, KP, killing four people. In 2009 an American employee of the U.S.-funded Federal Demonstrative Partnership was killed in Peshawar, KP. In the same year Pakistani workers of a USAID-funded NGO were attacked in Mansehra and three female workers were killed (Ahmed 2011, 6). Most attacks have happened where people have very little or no formal education and only rare access to information from the outside world. Therefore, they become easy victims of religious extremist propaganda and exploitation. Also, the aid workers are often ignorant of local dynamics and this creates trouble for foreign development organizations in countries like Pakistan. Most of the areas in which development work is done are poor and underdeveloped. In those places the majority of people are illiterate and rely on information and knowledge delivered through sermons. There is the example of the Swiss cross, which is displayed on the logo of the Swiss Agency for Development Cooperation, being seen as a Christian cross. In such an anti-Western context, visits by foreigners in these areas are viewed with great suspicion.

\section{Situating PCIA Theory and Tools}

In response to these issues and concerns, some international development organizations have incorporated a number of tools and practices of conflict sensitivity and PCIA into their programs. This section highlights the methodological value and diversity of these tools as used in Pakistan. The initial 
focus is on the conceptual similarities and differences among various conflict sensitivity guidelines. It also brings to light the lack of cooperation among international development organizations in the field.

As development agencies pursue different priorities and political directions, many create separate tools and guidelines on conflict sensitivity. In Pakistan, PCIA and related tools have appeared under the guise of Peace and Conflict Assessment (PCA), Conflict Sensitive Project Planning, and Political Economy and Conflict Analysis, to name the most prominent.

Although these discourses have contributed greatly to mainstreaming peace and conflict sensitivity, we are far from having a shared, routine application of concepts, methods and assessment criteria-as might be reflected, for example, in the standard procedures of organizations working in conflict-affected areas. (Paffenholz, AbuNimer, and McCandless 2005, 1)

These different methodologies and approaches, which result in a lack of coherence among donor organizations, stem from their assumed and diverse political orientations. The plethora of PCIA methodologies and approaches actually has little impact on the ground. To initiate collaboration among development organizations engaged in relevant work, it is important to depoliticize PCIA. However, cooperation relating to PCIA can only be initiated if international organizations engage in cooperation in other matters for greater success in development projects.

PCIA as a tool is different from others methods such as Conflict Sensitive Project Planning because it focuses equally on peace and conflict dynamics for the purpose of contributing to reduction of conflict and enhancement of peace. Thus, PCIA is also different from evaluation of projects. This distinction is made clear from the PCIA model that starts with conflict analysis for defining possible courses of action leading to conflict-sensitive project planning. PCIA concludes with conflict monitoring and review of impact hypotheses as a basis for adjusting projects, if needed.

From the outset, a country-specific conflict analysis makes donor policies more sensitive to local socio-political dynamics and, if carried out on a regular basis, offers organizations the opportunity to continue to adjust their projects in response to changing circumstances (Hoffman 2003, 27). For example, the conflict analysis undertaken by Friedrich Ebert Stiftung (FES) in Pakistan explored both the rising civil-military conflict as well as how youth were at risk of being exploited by extremist elements (Ahmed 2011, 5).

As well argued across literature and practice, it is not enough to conduct a single conflict analysis as the basis for an entire project cycle. The unstable and changing demographic, political, and external dynamics of Pakistan all point to the value of undertaking regular conflict analysis exercises. For 
example, Islamabad now has multiple, major ethnic groups because of the influx of thousands of settlers from KP, FATA and Karachi. Understanding these dynamic changes, and the ensuing relations between the implicated groups and communities, is one key reason for undertaking regular conflict analysis by and for those intent on intervening. However, as observed too frequently by the author, most international development agencies ignore the very significance of updated conflict analysis in Pakistan-something that also constrains conflict sensitivity. There are many reasons for this. For example, it is mostly consultants who do conflict analysis, meaning the local staff members are either not willing to take on the extra workload or do not have the capacity to do so. It is therefore important to integrate PCIA into ongoing development work. Another major reason is financial, as hiring a team of consultants incurs a substantial cost. Therefore, development agencies often avoid repeating that task within the same project cycle.

Research tools are often formulated by development agencies for project monitoring and evaluation. Although development evaluations can be systematic, they are generally inadequate for comprehensively evaluating the conflict and peace impacts of development projects. Indeed, little attention has been devoted to adapting such development evaluation methodologies to violent contexts (Paffenholz, Abu-Nimer, and McCandless 2005). In Pakistan, few foreign development agencies have made significant efforts to adapt development evaluations in accordance with peace and conflict dynamics.

The PCIA approach assumes that development programming has the potential for unintended negative consequences. It does not limit its assessment of projects to the program objectives, but also assesses the effects on peace and conflict. This approach goes beyond simple assessment. It is intended to promote conflict sensitivity by creating greater awareness of the interaction between a development intervention and the context. As noted by Bush (2003, 3), PCIA "is an extremely important and useful process that will help you ensure that the initiatives you are working on do not aggravate violent conflict and, as far as possible, contribute to building peace within and between communities." This shows that PCIA is a holistic model that should be applied in totality. As observed in Pakistan, often the focus of PCIA has been on the impacts of development interventions on conflict while ignoring the interaction of projects with peacebuilding processes.

\section{PCIA as Perceived by Practitioners in Pakistan}

This section is devoted to understanding the reasons why PCIA is not being applied in totality in Pakistan. These limitations are linked to lack of understanding, transparency, and good intent, as illustrated through practical 
examples below.

\section{Grounded Perceptions of PCIA}

Most international development interventions in Pakistan, as in many other countries, are implemented through local partner organizations (NGOs), and so international development organizations are rarely visible on the ground. Limitations caused by language and cultural barriers as well as insecurity limit the extent to which international development organizations can ensure the effectiveness of their initiatives. The situation is even more complex when it comes to the issue of PCIA. While PCIA guidelines, methodologies and tools abound, they are not well known nor understood at the project level.

In the survey of local and foreign staff members of NGOs and intergovernmental organizations (IGOs) doing development and peacebuilding work in Pakistan conducted for this research, $62.5 \%$ of respondents reported having some level of awareness of PCIA; the rest (37.5\%) had never heard of the approach. Ideally, donor organisations or international development actorssome of whom are the very creators of PCIA guidelines-should inform their partner organisations of PCIA. At present, this is clearly not the case in Pakistan. Out of the $62.5 \%$, all had learned about PCIA from other sources, such as the online training program of Eastern Mennonite University. Given that the application of PCIA in development work in Pakistan can be sensitive, it would appear that international donor agencies have simply avoided involving their local partners in discussions about PCIA and its applications. For this reason there is limited understanding of both theoretical and practical aspects of PCIA/ conflict sensitivity tools among people working on the ground with local and/or international development organizations. It is important to underscore that tools like PCIA help in developing a comprehensive understanding of local conflict and peace dynamics necessary for avoiding contextual and conflict insensitivity.

Almost all face-to-face interviews revealed that understanding of the concept of conflict sensitivity and its relevance to their work was not widespread among development workers. This lack of understanding is a major hurdle to PCIA's implementation. In Pakistan, processes of "risk assessment" are often confused with PCIA. The difference between a "risk and opportunity assessment" and a PCIA process is that the former looks into the impact(s) of a peace and conflict environment on an initiative or a project. In contrast, PCIA looks into the impact of an initiative or a project on peace and conflict environments (Bush 2003).

For improving PCIA in theory and in practice it is important to appraise the views of people applying it. According to the same survey, 25\% of those who had heard of PCIA found it useful, practical and effective. However, all of them suggested that PCIA needed modification to be effective in the Pakistani context. They specifically called for the inclusion of contextual case studies in PCIA training materials. This is an important recommendation because all too often 
PCIA tools are not user friendly, and also overly theoretical and unnecessarily complex for people on the ground.

Most people working for IDAs in Pakistan are not trained in the art of monitoring and evaluation. Among respondents, the ones who knew about PCIA wanted guidelines to be simpler and to the point with regard to the dos and don'ts of conflict sensitivity at the field level. Implementers of PCIA find it challenging because it is not only time consuming but also something they think they cannot accomplish alone due to their limited capacities. Indeed, both conflict analysis and monitoring require expert training. Further, this research found that there tends to be resentment among local staffers of IDAs, who consider the mainstreaming of PCIA to be an added burden on them.

\section{Lack of Local Participation}

In cases where PCIA is practiced, there is confusion regarding the sharing of PCIA-related information with local partner organizations, and often little attention is paid to transferring PCIA-related knowledge and skills to local NGO staff. In the cases of several foreign development agencies, workers from partner NGOs were not invited to trainings on PCIA conducted during 2006 and 2008. Furthermore, in those trainings there was no mention of including members of partner NGOs. This is a major flaw in the application of PCIA in Pakistan; procedures for involving partner NGOs in PCIA processes should be discussed and developed. Therefore, Kamatsiko $(2014,26)$ has suggested that "minimum standards for PCIA processes, methodology and content are needed." In the absence of such standards, there remains a lot of confusion among those implementing the approach.

For PCIA to be implemented successfully in contexts such as Pakistan, IDAs must decide on the appropriate level of participation of local partner organizations in PCIA processes. However, several structural factors hamper the training of local NGO staff in PCIA methodologies. Locals frequently view information-gathering exercises, such as those occurring within PCIA, as the work of foreign intelligence agencies. There is evidence available from other contexts, including Sri Lanka, where PCIA was seen as an effective tool for "intelligence gathering" (Achitei 2014, 44). As analyzed in context analysis, Pakistan is a context where many people have negative perceptions of Western aid and interventions in the country. Therefore, first there is a need to build rapport with local partners regarding PCIA and similar tools.

Lack of confidence in PCIA is a major constraint on the sharing knowledge related to the PCIA process between international donors and local partners, particularly when elements of the local population already distrust the agenda of development agencies. On the flip side, PCIA processes require a good understanding of local socio-political dynamics. Consequently, local NGO staff can be of immense value to IDAs in conducting such exercises. 


\section{Implementation}

Survey participants identified conflict as a relevant issue in development planning and acknowledged that increased conflict sensitivity might have helped them reduce the detrimental impacts of conflict on their work. However, the author observed that there was still some confusion in relation to where PCIA should be conducted within Pakistan. Bush $(2003,5)$ provides answers to this question:

PCIA should certainly be embedded in initiatives located in "hot" war zones. However, they should also apply to initiatives in a far wider range of conflict-prone settings-that is, places where there is a risk that non-violent conflict may turn (or return) to violence. This includes areas: (1) where the control over, or use of, territory or resources is disputed; (2) where the socio-economic gap between groups is increasing; or (3) where unemployment is rising while living standards and human security are declining.

In each of the aforementioned scenarios discussed by Bush, there is a likelihood of violence, and the application of PCIA in violence-prone contexts is highly relevant. Usually, PCIA promoters are faced with another, somewhat similar, question: Do we need to wait for escalation of conflict to apply PCIA? According to Charles Besancon $(2005,2)$, PCIA can be used in places with a "recent history of conflict, escalating tensions, and increasing risk of violence."

\section{Justifying PCIA}

Ideally, all development programs in conflict zones should contribute to wider peace processes. While not all development programs in conflict or conflictprone zones see this as part of their job, some international development actors have developed strategies for "working in, on and around conflict" (Paffenholz, Abu-Nimer, and McCandless 2005, 3). Due to natural limitations like insecurity and lack of capacity, international development organizations hesitate to become directly involved in peace-related work in Pakistan. Thus, either they do what they are doing-development work-at a lower scale or they just refrain from working in conflict-affected project areas. The following example is insightful in this respect.

Since 2002 the number of development activities in conflict-prone and conflict-affected areas of Pakistan has increased. It is difficult to avoid development projects from being influenced by conflict. There is the example of a European-funded, non-formal school project in Dera Ismail Khan, KP, which had to be closed due to the outbreak of a simmering conflict between two local groups, Powindah and Gandapurs (Ahmed, 2011). Considering this scenario, it was clear that to sustain their project, either the local NGO or the donor organization had to be aware of the situation and possibly to intervene. 
However, an intervention did not occur because both the donor organization and the local NGO preferred to avoid the dispute, considering it beyond the scope of their work. The NGO did not pull out, but also failed to do anything to resolve the conflict, choosing to wait for the conflict to be resolved on its own. In the meantime, the children suffered for lack of schooling.

While working in a conflict zone such as Pakistan, where several forms of conflict exist (sectarian, inter-religious, and ethnic), the option of conflict avoidance becomes a difficult one for development workers, especially when a conflict hinders their development work. The following examples highlight the importance of a conflict analysis exercise at the project level for avoiding unintended negative impacts on local communities. At the project level there are can be conflict over the sharing of natural resources, such as water, land and forests (Ahmed 2011, 8). After conducting a comprehensive context analysis a European organization implemented its irrigation project in an area affected by water shortage (Dera Ismail Khan in KP) and so was able to avoid involvement in local conflict. The analysis of the situation helped the implementing organization to refrain from putting its irrigation project under the influence of some elites who had been controlling water from upstream. The prior situation had expanded the rich-poor gap due to irrigation only reaching the lands of the influential farmers.

In conflict zones like Pakistan, the possibility of development workers becoming parties to conflict is heightened in situations where they are not familiar with the local context. Therefore, PCIA's first stage of conflict analysis at the project level can help a great deal in providing understanding of local sociocultural and political dynamics. There is an example from 2007 of a local NGOfunded by a European agency-getting into conflict with local people in Swat, KP. The conflict erupted because the local NGO was advocating for women's rights, which was perceived by imams to be a Western agenda. Then, intermediaries, who had been making a good profit by purchasing medicinal plants from collectors, were annoyed because the NGO provided direct market access to poor collectors. The local NGO was really faced with multiple conflicts with a diverse group of actors; it also got into a clash with a timber smuggling mafia group after bringing up the issue of illegal deforestation.

In another case, from the Swabi district, local NGOs working with IDAs became embroiled in conflict with communities where they were operating. These NGOs were labeled "outsiders" and were perceived to be propagating a Western, anti-Islamic agenda. Consequently, some Muslim extremist elements began spreading hate material attacking the NGOs. They also resented the fact that an IDA staff group, consisting of foreign men and women, visited an NGO in Swabi where local women were working. Additionally, community members were saying that local NGO staff were being Westernized.

Finally, in the best of circumstances development workers are able to address 
and creatively transform potential conflict issues. For instance, cultural sensitivity is a serious issue and, indeed, cultural insensitivity may harm development workers and their worthwhile initiatives in Pakistan. The way in which such actors choose to make sense of the cultural knowledge generated by conflict analysis exercises may inform the practice of PCIA and support more effective interventions.

Due to age-old cultural practices, women from the northwest of Pakistan observe purdah and wear the burka. Segregated groups of men and women are organized for all social gatherings, such as weddings. These customs also affect the NGOs working in these areas. Thus, in some cases, women cannot attend or participate in public activities alone. Aware of this, some development agencies in KP have allowed and financed one man to accompany each participating woman in order to increase the possibility and effectiveness of women's participation in activities. These changes in development interventions reflect respect for local cultures and traditions, an example of conflict sensitivity.

\section{Overcoming Constraints to the Application of PCIA}

Despite the evident merits of PCIA for development organizations and their partners, its application in Pakistan is constrained by many factors, including financial, methodological, programmatic, and even political. The following section discusses some of the most salient constraints and suggests ways to overcome them.

Only a few organizations have the capacity and mechanisms in place to pursue and properly follow up on PCIA in conflict and conflict-prone zones. The situation has worsened since the 2008 global financial crisis because the operations of many development agencies experienced huge budget cuts.

Even if these organizations train their local staff, there remains a gap between the theory and implementation of PCIA, since most of their employees either remain confused about the intent and practice of PCIA or are just not willing to take up the extra workload involved in implementing the approach in his/ her development projects. This could be a reason that another study conducted in Pakistan (Zicherman et al. 2011) found little evidence of the explicit use of conflict sensitivity tools in emergency responses. It has also been found that only few local project personnel have the ability to assess the existence of conflict(s).

All development stakeholders must be clear that "PCIA is an on-going and dynamic approach taken before, during, and after a particular intervention in a conflict-prone region" (Bush 2003, 6). PCIA is designed to be used at all stages in a project cycle, from project design, to implementation, and evaluation. (Besancon 2005). Unfortunately, PCIA is often perceived to be outside the normal project cycle. 
PCIA, when it is employed, is often an expert-driven exercise reliant on external consultants for analysis. When a consultant arrives, he/she frequently accomplishes assessment tasks independently. Thus, there is no transfer of knowledge from a skilled person to local staff, and PCIA is rarely repeated given the prohibitive cost. Because of the confinement of knowledge to external consultants or expatriate staff, PCIA practice and potential have been constrained. Foreigners naturally encounter some limitations in a context where they are short-term visitors. They depend on local staff intimately familiar with local dynamics for even the basics, at least initially. Thus, PCIA and similar tools should be implemented in consultation with staff of local NGOs. In addition, the process of consultation at local levels should include some prominent local community leaders. The failure to do so has been a constraint.

PCIA needs to be transparent, shared and people-centered. The real experts of PCIA are those women, men, girls and boys living in conflict zones. If they are not centrally involved in peace and conflict analysis and interpretation, then the exercise will fail, or worse, will disempower communities-that is, it will remove them from decisions that fundamentally affect their lives. If a community does not believe a PCIA is genuine or legitimate; if they believe that it will be used to force unwanted projects or decisions on them; then they are completely justified in rejecting the process and its outcomes. (Bush 2003, 6)

The question of local partner involvement remains a challenge for almost all stakeholders, especially international development actors. There are associated fears that local partners might perceive PCIA as yet another agenda of the West or some sort of project evaluation mechanism leading to a significant reduction in funding. This shows that there are some misperceptions relating to PCIA that can be eliminated with the help of more awareness of conflict sensitivity.

What should be the minimum duration of various stages in PCIA for ensuring that this tool is implemented in a way that will achieve its greatest value? Often PCIA is implemented in several disconnected episodes or combining all stages at once. Sometimes consultants are hired to conduct a PCIA exercise in one or two weeks. According to the "father of PCIA," Kenneth Bush $(2003,6)$, "a rushed PCIA is a doubtful PCIA." PCIA does take time; under demanding circumstances in conflict-prone regions, PCIA processes have to develop roots that dig deeper into a particular context. This can be done slowly and steadily through various PCIA steps, as explained earlier in the article.

Tools like PCIA cannot be implemented piecemeal, for example by skipping any of its stages. In the case of Pakistan, it was observed that some organizations had adopted PCIA without the crucial first step of conflict analysis. In some cases examined in this research, conflict analysis was not done before project design and implementation. Consequently, PCIA was only partially implemented, focusing on analysis of a project's impact on the local peace and conflict divisions. 
Some development donors appreciate this approach as it consumes significantly less time and resources. Local staff workers, at the behest of the IDA headquarters, are usually the ones who undertake most such hurried and truncated applications of PCIA.

A comprehensive PCIA exercise provides some answers to the questions and challenges posed above but not without raising a number of other concerns. Most crucially, one does not know what would have happened in a particular peace and conflict environment without the specific development intervention under observation.

\section{Conclusion}

As argued in this article, PCIA, if applied in totality, is a meaningful tool for conflict avoidance and for contributing to peace. However, in Pakistan and other similar conflict-prone contexts, PCIA is generally seen by its implementers to be complex, expansive, and irrelevant (Zicherman et al. 2011). There are diverse understandings of PCIA among all stakeholders, which is a major problem as far PCIA's implementation and wider acceptance is concerned.

In light of the findings outlined here, it is suggested that a more thorough awareness campaign regarding conflict sensitivity should be initiated in Pakistan and similar conflict zones targeted to both international and local NGOs. Furthermore, there should be greater focus on the capacity building of local development actors, something that can be done by expatriates in development circles. These goals can only be achieved by integrating PCIA into the program cycle, because otherwise it will be seen as an add-on to the "real work." It is now time to depoliticize PCIA, meaning that development agencies should disconnect the process from any political agenda (such as intelligence gathering) and rather work together with local partners to develop and implement PCIAs in the context of development projects. Such jointly pursued PCIA exercises are not only likely to be more fruitful on the ground, but would also put into practice the collaborative culture that these agencies seek to encourage.

\section{Notes}

This article is an expanded version of an unpublished paper presented at the International Peace Research Association (IPRA) 2014 General Conference, Istanbul, August 11-15, 2014. 
1. These organizations are not named in order to preserve their anonymity.

\section{References}

Abitbol, Eric. 2014. "Assessing the Power and Practices of Peace and Conflict Impact Assessment (PCIA)." Journal of Peacebuilding \& Development 9 (1): 3-9.

Achitei, Simona. 2014. "Mainstreaming Failure or a Small Measure of Success? Observations from a Large-Scale PCIA in Post-War Sri Lanka." Journal of Peacebuilding \& Development 9 (1): 44-58.

Ahmed, Zahid S. 2011. "Peace and Conflict Impact Assessment (PCIA): Lessons from Pakistan." Peace \& Conflict Review 5 (2): 1-12.

Al Jazeera. 2014. "Polio workers killed in Pakistan attack." November 26. http:// www.aljazeera.com/news/asia/2014/11/polio-workers-killed-pakistan-attack20141126556854951.html (accessed August 30, 2015).

Anderson, Mary B. 1999. Do No Harm: How Aid Can Support Peace-or War. London: Lynne Rienner Publishers.

Besancon, Charles. 2005. "Peace and Conflict Impact Assessment Brainstorming Workshop Report." Kigali, Rwanda: International Institute of Sustainable Development.

Bush, Kenneth. 1998. "A Measure of Peace: Peace and Conflict Impact Assessment (PCIA) of Development Projects in Conflict Zones." Working Paper No. 1. Peacebuilding and Reconstruction Program Initiative \& Evaluation Unit. Ottawa: IDRC.

Bush, Kenneth. 2003. "Hands-on PCIA: A Handbook for Peace and Conflict Impact Assessment (PCIA)." The Federation of Canadian Municipalities and the CanadianPhilippines Local Government Support Program. http://portals.wi.wur.nl/files/docs/ ppme/Hands_On_PCIA_Handbook_BUSH_Final_Author_Version1.pdf (accessed August 1, 2014).

Census of Pakistan. 1998. Population Census Organization. Islamabad: Ministry of Economic Affairs and Statistics.

Crilly, Rob. 2012. "US Drone Attack Kills Four Militants in Pakistan.” The Telegraph (UK), September 28.

Economist. 2012. "Killing disease: Pakistani attacks on aid workers." December 22. http:// www.economist.com/news/asia/21568773-grisly-attacks-pakistan-target-thosedoing-good-children-killing-disease (accessed August 30, 2015).

FES (Friedrich Ebert Stiftung). 2007. Peace and Conflict Impact Assessment: Methodical Guidelines. Berlin: FES.

Hammill, Anne, and Charles Besancon. 2003. "Promoting Conflict Sensitivity in Transboundary Protected Areas: A Role for Peace and Conflict Impact Assessments." Paper prepared for the workshop on Transboundary Protected Areas in the Governance Stream of the $5^{\text {th }}$ World Parks Congress. Durban, South Africa: International Institute of Sustainable Development.

Hoffman, Mark. 2003. “PCIA Methodology: Evolving Art Form or Practical Dead End?” In Peace and Conflict Impact Assessment, eds. A. Austin, M. Fischer, and O. Wils. Berlin: Berghof Research Center for Constructive Conflict Management, 11-35. 
HRCP (Human Rights Commission of Pakistan). 2010. State of Human Rights in 2010. Lahore: HRCP.

Institute for Economics and Peace. 2014a. Global Peace Index - 2014. Sydney: IEP. Institute for Economics and Peace. 2014b. Global Terrorism Index - 2014. Sydney: IEP. Javid, Muhammad, and Abdul Qayyum. 2011. Foreign Aid and Growth Nexus in Pakistan: The Role of Macroeconomic Policies. Islamabad: Pakistan Institute of Development Economics.

Kamatsiko, Valarie Vat. 2014. "PCIA Theory and Field Practice: World Vision's Pursuit of Peace Impact and Programming Quality across Sectors." Journal of Peacebuilding \& Development 9 (1): 26-43.

Macabuac-Ferolin, Maria Cecilia, and Norma V. Constantino. 2014. "Localizing Transformation: Addressing Clan Feuds in Mindanao through PCIA." Journal of Peacebuilding \& Development 9 (1): 10-25.

Malik, Kabir. 2005. "Madrisas and Enlightened Moderation.” Pak Tribune, September 20. http://paktribune.com/news/index.php?id=119691 (accessed August 13, 2015).

McCandless, Erin. 2014. "Revitalizing Our Tools to Better Engage Local Contexts and Measure and Promote Peace." Journal of Peacebuilding \& Development 9 (1): 1-2.

Paffenholz, Thania, Mohammed Abu-Nimer, and Erin McCandless. 2005. "Peacebuilding and Development: Integrated Approaches to Evaluation." Journal of Peacebuilding and Development 2 (2): 1-5.

Population Census Organization. 2013. Ministry of Economic Affairs and Statistics. http:// www.census.gov.pk/ (accessed August 7, 2014).

SDC (Swiss Agency for Development and Cooperation). 2006. "Conflict-Sensitive Program Management CSPM: Integrating Conflict Sensitivity and Prevention of Violence into SDC Programs." Bern: SDC.

Siddiqa, Ayesha. 2007. “The Politics of USAID.” Newsline, December 11. http://www. newslinemagazine.com/2007/12/the-politics-of-us-aid/ (accessed September 30, 2015).

Stoddard, Abby, Adele Harmer, and Katherine Haver. 2006. Providing Aid in Insecure Environments: Trends in Policy and Operations. London: Overseas Development Institute.

Stoddard, Abby, Adele Harmer, and Victoria DiDomenico. 2009. Providing Aid in Insecure Environments: 2009 Update. London: Overseas Development Institute.

Stoddard, Abby, Adele Harmer, and Kathleen Ryou. 2014. Aid Worker Security Report. London: Humanitarian Outcomes.

Zicherman, Nona, Aimal Khan, Anne Street, and Oliver Chevreau. 2011. Applying Conflict Sensitivity in Emergency Response: Current Practice and Ways Forward. London: Overseas Development Institute.

Zahid Shahab Ahmed is Assistant Professor at the Centre for International Peace \& Stability (CIPS), National University of Sciences \& Technology (NUST), Pakistan. He is the author of Regionalism and Regional Security in South Asia: The Case of SAARC (Ashgate Publishing Ltd, 2013). E-mail: aprofpcscips@nipcons.nust.edu.pk. 
